\title{
Application of IOT in English Teaching of Ethnic Colleges
}

\author{
Wang Zhengwei Li Yueguang \\ Gansu Normal College for Nationalities, Hezuo, gansu ,747000, China \\ Yueguangli7@163.com
}

\begin{abstract}
This paper firstly introduces the basic content of Internet of things and the application in all walks of life. In view of English teaching problems in ethnic colleges, combined with the advantages of Internet of things, taking Gansu Normal College for Nationalities as an example, a new English teaching model based on the Internet of things of national education is discussed, the model integrates the teaching resources of various ethnic colleges, it provides more efficient, excellent service for the majority of teachers and students, it is useful to improve the English teaching effect of ethnic colleges.
\end{abstract}

Keywords: Internet of things (IOT); English teaching; Gansu Normal University for Nationalities; Teaching model.

\section{Introduction}

The concept of IOT was proposed in 1999 when based on standard of Internet, RFID technology and EPC, and even Computer Internet, the RFID Technology and wireless data communication technology etc were employed to construct internet in kind that achieved share in actual time in global materialistic information $^{[1]}$.

There is a great difference between IOT and Internet that IOT directly connects various kinds of Information transmitting Equipments, and there is no need of inputting information by keyboard, but automatically attaining information and spontaneous disposal ${ }^{[2]}$.

\section{Characteristics and Functions in Application of Iot in English Teaching of Ethnic Colleges}

Language learning is a greatly practical course that is needed to make more practice done by students in extracurricular time. According to scientific estimation one English learner needs to spend 2500 hrs so as to have strong desire to achieve intermediate level with good proficiency and efficiency. If one university student who would like to arrive at the intermediate level in English language perhaps should spend about $2 \mathrm{hrs}$ to learn English everyday in the periods of 8 semesters, that is, 14 hrs every weeks and $61 \mathrm{hrs}$ every months. And in the light of the latest revised College English Teaching Syllabus in GanSu Normal University for Nationalities, the prescribed time is only $380 \mathrm{hrs}$ within college class, that is to say, the proportion between the time used in extracurricular pre-reading and assignment and that in class to be listener is $6.6: 1$ is applied to reach the teaching requirements. In order to lead students to spend more time to learn English in extracurricular time, a remedy method universally employed is to hew out such second classes as English Corner, Campus magazine and English broadcasting, etc. the best advantage of the second class is to make students get in 
touch with English, yet, the greatest shortcoming is inconvenient to effectively control over individuals by teacher who can ensure each students to participate in English learning and also to get benefits in the degree of equivalence ${ }^{[3]}$. Whereas there are some reasons such as geographical location and students' conditions available in GanSu Normal University for Nationalities, the second class should be awfully strengthened. In order to motivate students to learn English actively in extracurricular time without any abandoning themselves to useless things, and also to effectively examine the progress of extracurricular learning done by students, this text attempts to introduce IOT into English teaching in GanSu Normal University for Nationalities.

Below-mentioned characteristics introduced into IOT English Teaching:

(1) The basic motivation of introduction of IOT into English teaching is to maximum extension to get engaged in practical English and to swiftly improve English level in all aspects.

(2) The introduction of IOT may get through inherent model of learning in all aspects of attending lecture in class, notetaking and reviewing notes taken and writing homework, etc and stimulate students to master over English as means of entertainment and communication

(3) In favor of teaching students in accordance of their aptitude. Teacher can choose materials that fit for students in accordance of different levels, while students can proceed with learning in terms of comfortable progress made in extracurricular periods ${ }^{[4]}$.

\section{Information obtained in interactive teaching System of iot}

There are Minorities such as Tibetan, Hui People, Han People, Tu People and Mongolia, etc available in Gansu Nor- mal University for Nationalities who have their own characteristics in speech mouth style and intonation and frequency which can be described from points of physiology and physics compared with English Standard Month style and standard speech by digitalized cameral shooting and speech recording, and then, the relative software of it shall be compiled with standard English speech and function of mouth style model as well as revising function of English speech and mouth style and also with assessment for English Learners. Figure one is to make description of major parameter of Mouth style including width of oral cavity open, degree of oral cavity inside open, degree of oral cavity outside open and degree of face bugle, etc. in order to attain digital information of standard mouth style when in the state of English speech and to compile software with revising function by making comparison among these above-mentioned parameters.

Figure two is the major technology parameters of English speech. It contains frequency, intonation and range, speech speed, etc. are used to attain technology indicator of English speech.

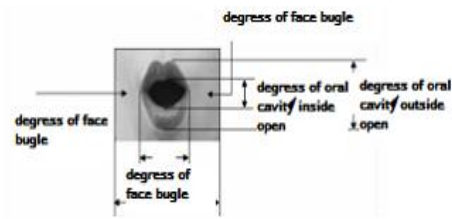

Figure 1 The major parameters of oral cavity

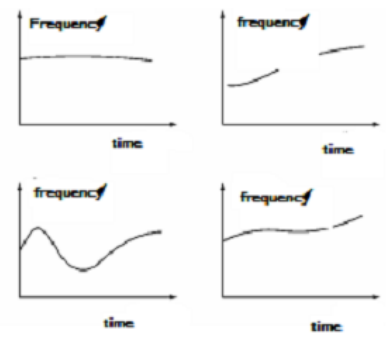

Figure 2 The major technology indicators of English Speech 


\section{Foration and Operation Principle of Iot Interactive Teaching System in Gansu Normal University for Nationalities}

Figure three is diagrammatic drawing for Format ion and operation principle of IOT Interactive Teaching System developed by Gansu Normal University for Nationalities in which the role of transducer is to make mouth style of IOT taken into system when in the state of English learners' speech as compared with standard mouth style memorized. And speech transducer is mainly applied for frequency, intonation and speech analysis. The system has learners' machine, LAN Control Center, systematic images and speech-processing software, etc as often used. And another, LANS is connected by optical fiber.

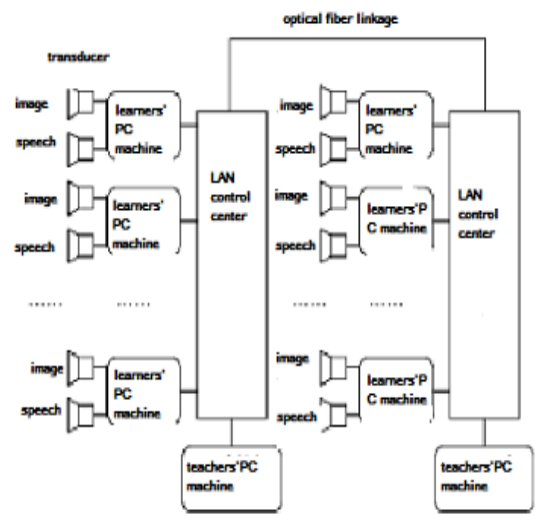

Figure 3 Formation and operation principle of IOT Interactive Teaching System

\section{Impleentation Upon Interactive Teaching System of Iot in Gansu Normal University for Nationalities (Gnun)}

IOT Website targets seeing IOT as the second class in accordance of Teaching objectives and Human Resource Development program in GNUN for the purpose of its being an auxiliary method and model so that English interaction website provides service for all students on campus and becomes foreign language teaching base of IOT. The website is fully used to mobilize and motivate zeal and enthusiasm in foreign language learning and the virtual environment is created by a series of activities and the application of multimedia courseware.

Teaching parts of IOT directly included in homepage of Foreign Language Department(FLD) is composed of the following components: courseware learning, communication online, English Forum, and Introduction of Faculty in GNUN, Public Notice, Friendship interlink and entertainment, etc, all which are compiled by using ASP Program and its data base 'ACCESS' that have powerful function and are used flexibly. Courseware learning partly provides English Teaching ${ }^{[5]}$.

IOT also needs to establish paper test base that suit for sophomore and Junior in Bachelor Degree and that is being developed. The development of paper test base should be satisfied with teachers and students who can take out and set some subjects at random in the paper test for practices. The model of courseware learning consists of three parts: login system, enter system, CAI Teaching Courseware (Internet Edit ion) and other courseware. The login system is used for students' registration information that is kept in ACCESS Base; enter system for checking account No and password of users and collecting registration information such as real name, faculty and class, etc from base that can be kept in another chart for checking learning conditions of students. Some Teaching courseware which is provided by teachers and then uploaded to server can be employed by teachers and students at any time. 


\section{Problems Existing and Improve- ment Measures at Present}

Although IOT auxiliary teaching has got universal acknowledged and admitted, yet in practical teaching most of teachers are still sticking to traditional teaching way with one chalk, one blackboard and self-inculcated teaching by teachers. Hereby, theoretical studies on teaching should be reinforced including Theory on IOT learning, IOT courses and Teaching theory and theory on IOT education transmission so as to make teachers control over IOT teaching.

It is not only necessary for teachers but for students to have correct understanding of self-directed learning. On one hand, teachers have play a dominant role that can't be neglected, otherwise it will cause students to lose control over learning. Therefore, in the course of teaching teachers should critically strengthen guidance and supervision upon students. On the other hand, students don't look at self-directed learning as unrestrained learning, and also suppose that self-directed learning advocated is not controlled over by teachers just as doing what they wished to do at random, instead, students should be convinced of the fact that successful learners generally who has a strong ability of self-control not only master over techniques and strategies engaged with various learning activities and solutions proposed to various learning difficulties but also choose proper disposal methods in accordance of specific learning tasks.

\section{Conclusion}

To sum up, the application of IOT as an auxiliary method will have an invaluable influence upon English teaching. Through being hard-working of all teachers, IOT will definitely become a pillar force in English teaching and serve as English teaching at all levels. It will be greatly helpful for optimizing learning environment, making the learning source affluent and improving learning manner, saving management cost and promoting management efficiency, swiftly carrying forward the progress of English education modernization

\section{References}

[1] $\mathrm{Pu}$ Hongmei. Discussion on the networking technology[J]. Science and technology information, 2010 (2): 191 $-191$.

[2] Gu PeiYa. Internet and Foreign Language Teaching $[\mathrm{J}]$. E-Teaching in Foreign Language, 1998 (4) : 22.

[3] Mo JingGuo. Beginning: The development of Resource Base of Self-directed College English Learning $[\mathrm{J}]$. E-Teaching in Foreign Language, 2005 (2) : 36.

[4] KITAO KENJI. Teaching the English newspaper effectively $[\mathrm{J}]$ The Internet TESL Journal，1996（3）.

[5] Chen JianLin. Theoretical connotation and Analysis of Application on Internalized Teaching of College English $[\mathrm{J}]$. E-Teaching in Foreign Language, 2004 (6) : 46. 